\title{
Características de carcaças de bovinos Nelore inteiros vs castrados em duas idades, terminados em confinamento
}

\author{
Aline Kellermann de Freitas ${ }^{1}$, João Restle ${ }^{2}$, Paulo Santana Pacheco ${ }^{3}$, João Teodoro Padua ${ }^{4}$, \\ Moacir Evandro Lage ${ }^{4}$, Eliane Sayuri Miyagi ${ }^{3}$, Gustavo Feliciano Resende da Silva ${ }^{5}$
}

\author{
${ }^{1}$ PPGCA - UFG. Bolsista CNPq. \\ 2 Pesquisador Visitante/CNPq - DPA/UFG. \\ 3 PPGCA - UFG. Bolsista CAPES. \\ ${ }^{4}$ Departamento de Produção Animal - UFG. \\ ${ }^{5}$ Graduando Medicina Veterinária - UFG. Bolsista CNPq.
}

RESUMO - Objetivou-se avaliar os rendimentos em carcaça e cortes primários de bovinos da raça Nelore, submetidos aos tratamentos: $\mathrm{C} 13$ = castrados aos 13 meses de idade $(\mathrm{n}=26) ; \mathrm{C} 18=$ novilhos castrados aos 18 meses de idade antes do confinamento $(n=26)$ e INT = novilhos inteiros $(n=25)$. Os animais foram confinados por 100 dias, recebendo dieta com 12\% de proteína bruta, 2,9 Mcal de energia digestível/kg de matéria seca (MS) e relação volumoso:concentrado de 60:40 (base na MS), e abatidos aos 22 meses de idade. O delineamento experimental utilizado foi o inteiramente casualizado. Os INT apresentaram maiores pesos ao abate $(395,00 \mathrm{~kg})$, de carcaça quente $(214,89 \mathrm{~kg})$ e de carcaça fria - PCF (212,21 kg) que os castrados, não ocorrendo diferenças entre os castrados. Os INT apresentaram maior rendimento de carcaça fria $(53,71 \%)$ e área de olho-de-lombo (AOL) $\left(61,23 \mathrm{~cm}^{2}\right)$ que os C13 (51,99\% e 56,59 $\mathrm{cm}^{2}$, respectivamente), não havendo diferenças entre C13 vs C18 e C18 vs INT. A condição sexual não influenciou o rendimento de carcaça quente, a perda por resfriamento da carcaça, AOL/100 kg PCF, comprimento de carcaça, comprimento e perímetro do braço e peso de ponta de agulha. Os INT apresentaram menores valores para espessura de gordura em relação aos castrados, que não diferiram entre si. Machos INT apresentaram maior percentual de dianteiro $(40,13)$ e menores de ponta de agulha $(10,22)$ e de traseiro $(50,24)$ em relação aos C13 (38,33; 11,09 e 51,77, respectivamente) e C18 (38,82; 10,73 e 51,46, respectivamente), que não diferiram entre si. Em valores absolutos, os INT apresentaram maior peso de dianteiro que os castrados, que não foram diferentes entre si, e maior peso de traseiro que os C13.

Palavras-chave: acabamento da carcaça, Bos indicus, condição sexual, idade de castração, qualidade da carcaça, sistema de terminação

\section{Carcass characteristics of Nellore cattle kept intact or castrated at two ages, feedlot finished}

\footnotetext{
ABSTRACT - Carcass dressing and primary cuts of Nellore cattle, submitted to the treatments: C13 = steers castrated at 13 months of age $(n=26)$; C18 = steers castrated at 18 months of age before feedlot $(n=26)$ and INT = intact males $(n=25)$ was evaluated in this researach. The animals were confined per 100 days, fed diet with $12,0 \%$ crude protein, 2.9 Mcal of DE/kg DM and forage to concentrate ratio of 60:40 (\% DM), and slaughtered at 22 months of age. A completely randomized experimental design was used. The INT animals showed higher slaughter weight $395.0 \mathrm{~kg}$, hot (214.89 kg) and cold - CCW (212.21 kg) carcass weights then castrated, without differences between castrated at different ages. The INT animals showed higher cold dressing percentage (53.71\%) and Longissimus dorsi muscle area (LDA) $\left(61.23 \mathrm{~cm}^{2}\right)$ in relation to C13 (51.99\% and $56.59 \mathrm{~cm}^{2}$, respectively), without differences between C13 vs C18 and C18 vs INT. The sexual condition did not influence hot dressing percentage, chilling loss, LDA/100 kg CCW, carcass length, arm length and perimeter, and side cut. The INT animals showed lower values for fat thickness in relation to castrated, that did not differ between them. The INT animals showed higher percentage for forequarter (40.13) and lower for side cut (10.22) and saw cut (50.24) than C13 (38.33; 11.09 and 51.77, respectively) and C18 (38.82; 10.73 and 51.46, respectively), without difference between them. In absolute values, INT animals showed higher forequarter weight than castrated, which did not differ between them, and higher saw cut weight than C13.
}

Key Words: Bos indicus, carcass fatness, carcass quality, castration age, finished system, sexual condition 


\section{Introdução}

O uso de animais inteiros que produzem hormônios naturais, como a testosterona, para produção de carne é, segundo Restle et al. (2000 a),uma alternativa viável para tornar o sistema de produção mais eficiente. Os hormônios andrógenos provenientes dos testículos parecem ter maior efeito na fase em que os animais têm maior incremento de peso, proporcionado pelo melhor nível nutricional. Isto foi verificado no sul do País por diversos autores (Restle et al., 1994b; Pereira, 1999) e nos Estados Unidos (Field, 1971; Lee et al., 1990). No entanto, são poucas as informações existentes a este respeito, tamanha a expressividade do rebanho na região centro-oeste (Ribeiro et al., 2004; Ruiz et al., 2005).

Quanto às características de carcaça, maiores pesos de abate, de carcaça quente e de carcaça fria para novilhos inteiros em relação aos castrados são relatados nos estudos de Euclides Filho et al. (2001), quando submetidos aos sistemas mais intensivos, como, por exemplo, o uso do confinamento.

A menor deposição de gordura na carcaça de animais inteiros é amplamente divulgada na literatura. No entanto, esta menor espessura de gordura somente é importante quando estiver abaixo do mínimo de $3 \mathrm{~mm}$, exigido pelos frigoríficos. A terminação em confinamento aparentemente resolve o problema, pelo menos em animais de grupos genéticos com precocidade para deposição de gordura. Em machos terminados em confinamento dos 20 aos 24 meses de idade, a espessura de gordura nos animais inteiros foi de 1,06; 3,70; 3,25 e 2,67 mm, respectivamente, para os grupos Charolês (C), Nelore (N), 1/2C1/2N e 1/2N1/2C. Já nos animais castrados, a espessura de gordura, citada na mesma ordem, foi de 2,14; 5,86, 4,00 e 5,17 mm (Restle et al., 1999).

Se for necessária a castração, quer pela exigência específica de algum mercado ou mesmo para aumentar a deposição de gordura, o interessante é retardar a sua realização visando aproveitar ao máximo a ação anabolisante dos hormônios andrógenos sobre o desenvolvimento dos animais. Isto resultará em maior peso por ocasião do abate, conforme constatado por Restle et al. (1994 b). No entanto, esses autores avaliaram os efeitos da idade de castração apenas até os 12 meses de idade.

Objetivou-se com este experimento avaliar as características de rendimento de carcaça e cortes primários das carcaças, medidas corporais e medidas indiretas de rendimento de cortes secundários de bovinos da raça Nelore, inteiros ou castrados em duas idades (13 ou 18 meses), terminados em confinamento e abatidos aos 22 meses de idade.

\section{Material e Métodos}

O experimento foi conduzido na Fazenda Tangará, localizada no município de Mozarlândia - GO, no período de janeiro a novembro de 2004. As avaliações da carcaça foram realizadas no frigorífico Goiás Carne Ltda.

Foram utilizados 77 novilhos contemporâneos da raça Nelore, com peso médio inicial de $222 \mathrm{~kg}$, submetidos a três tratamentos: $\mathrm{C} 13=$ machos castrados aos 13 meses de idade, na fase de recria $(\mathrm{n}=26)$; $\mathrm{C} 18=$ machos castrados aos 18 meses de idade, 15 dias antes da fase de terminação $(\mathrm{n}=26)$ e INT = machos inteiros $(\mathrm{n}=25)$. O método de castração utilizado foi o cirúrgico, removendo-se os testículos por incisão do ápice do saco escrotal.

Durante a recria, fevereiro a julho, os animais foram mantidos em pastagem de Brachiaria brizantha cv. Marandu, com suplementação mineral, pelo método de lotação contínua (dois animais/ha). A partir de agosto, os animais foram confinados com peso médio inicial de $290 \mathrm{~kg}$ e receberam dieta formulada de acordo com o NRC (1996), com relação volumoso:concentrado de 60:40, base na matéria seca (MS) e dieta contendo 12\% de proteína bruta e 2,9 Mcal de energia digestível/kg de MS. A fração volumosa foi silagem de milho e o concentrado composto por farelo de soja, milho em grão moído, caroço de algodão e núcleo mineral. Os animais foram alimentados à vontade, três vezes ao dia e abatidos após 100 dias de confinamento, com 22 meses de idade média.

Antes do embarque para o frigorífico, os animais foram pesados após jejum de sólidos de 12 horas e abatidos seguindo o procedimento e o fluxo normal do frigorífico. No final da linha de abate, as carcaças foram divididas em duas metades e pesadas para obtenção do peso de carcaça quente, sendo identificadas e encaminhadas à câmara de resfriamento por 24 horas à temperatura em torno de $0^{\circ} \mathrm{C}$.

Após o período de resfriamento, as meias-carcaças foram novamente pesadas para obtenção do peso de carcaça fria. Com estas duas pesagens, foram calculados os rendimentos de carcaça quente e fria, baseado no peso de abate, e a quebra no processo de resfriamento por diferença (\%) no peso de carcaça quente e fria.

A meia-carcaça fria esquerda foi separada nos cortes primários: traseiro especial, que compreende a região posterior da carcaça, separado do dianteiro entre a quinta e sexta costelas e da ponta de agulha à distância de aproximadamente $20 \mathrm{~cm}$ da coluna vertebral; dianteiro, que compreende pescoço, paleta, braço e cinco costelas; e ponta de agulha, que compreende a região da sexta costela mais os 
músculos abdominais. Os cortes foram pesados individualmente e determinadas suas proporções em relação à meia-carcaça fria.

Na meia-carcaça fria direita, foram avaliadas as seguintes características métricas: comprimento de carcaça, tomada do bordo cranial medial da primeira costela e o bordo anterior do osso púbis; comprimento do braço, medido da articulação rádio carpiana até a extremidade do olécrano; e perímetro do braço, determinado pelo perímetro da região medial do mesmo.

Ainda na meia-carcaça fria direita, na altura da $12^{\mathrm{a}}$ costela, sobre a face exposta do músculo Longissimus dorsi, foi traçado em papel vegetal o seu contorno para posterior determinação de sua área $\left(\mathrm{cm}^{2}\right)$, denominada área de olho-de-lombo (AOL), por intermédio do software Autocad ${ }^{\circledR}$. Também foi determinada a espessura de gordura subcutânea, pela média aritmética de duas medidas ao redor do músculo Longissimus dorsi exposto (Müller, 1987).

O delineamento experimental utilizado foi o inteiramente casualizado, com três tratamentos, sendo cada animal considerado uma repetição. O modelo matemático utilizado foi: $\Upsilon_{i j}=\mu+\mathrm{t}_{i}+\mathrm{e}_{i j}$, em que: $\Upsilon_{i j}=$ variáveis dependentes; $\mu=$ média geral de todas as observações; $\mathrm{t}_{i}=$ efeito do tratamento de ordem “ $i$ ", sendo $1=\mathrm{C} 13$, 2 = C18 e 3= INT; $\mathrm{e}_{i j}=$ erro aleatório residual, $\operatorname{NID}\left(0, \sigma^{2}\right)$.

Os dados foram submetidos à análise de variância, sendo aplicados os testes F e Tukey, a 5\% de significância, utilizando-se o programa estatístico SAS (1997). Foram realizadas análises de correlação de Pearson e de contraste entre novilhos castrados (C13 e C18) e INT. Os dados foram testados previamente quanto à normalidade, por intermédio do teste Shapiro-Wilk (SAS, 1997), sendo efetuada, quando necessário, a transformação da raiz quadrada dos dados.

\section{Resultados e Discussão}

Os animais inteiros (INT) apresentaram maiores $(\mathrm{P}<0,05)$ pesos de abate, de carcaça quente e de carcaça fria em relação aos castrados aos 13 (C13) e 18 (C18) meses de idade, sendo estes dois últimos similares $(\mathrm{P}>0,05)$ (Tabela 1). Com isso, manter os bovinos INT representou superioridade de 5,1; 7,0 e 8,0\%, respectivamente, no peso de abate, de carcaça quente e de carcaça fria. Com relação às características da carcaça, Costa et al. (2002) comentam que o peso e o rendimento de carcaça são de grande interesse comercial para os frigoríficos, pois determinam o valor do produto adquirido e dos custos operacionais, uma vez que carcaças com pesos diferentes demandam a mesma mão-de-obra e tempo de processamento. Atualmente, o peso de carcaça quente é a forma de comercialização mais utilizada pelos frigoríficos, que normalmente desejam peso mínimo de $230 \mathrm{~kg}$.

Maiores pesos de abate e carcaça quente e fria para os bovinos INT em relação aos castrados foram relatados nos estudos de Arthaud et al. (1977), Restle et al. (1994 a), Restle et al. (1996), Restle \& Vaz (1997), Restle et al. (2000 b), Euclides Filho et al. (2001), Padua et al. (2004) e Tullio (2004). Quando submetidos a sistemas mais intensivos, onde a condição nutricional não é fator limitante ao desempenho dos animais, como o confinamento a que estes animais foram submetidos, Lee et al. (1990) e Restle et al. (1994 b) comentaram que as diferenças no desempenho entre animais inteiros e castrados são mais acentuadas, a favor dos inteiros. Isto devido à maior ação hormonal proveniente dos hormônios androgênicos, entre eles a testosterona, produzida nos testículos (Field, 1971).

Com os objetivos de melhorar o desempenho e tentar minimizar a perda de peso anterior ao confinamento, aproximando o peso dos animais castrados ao dos inteiros,

Tabela 1 - Médias e erros-padrão para peso de abate, pesos de carcaça quente e fria, rendimentos de carcaça quente e fria e perdas por resfriamento da carcaça de bovinos Nelore castrados aos 13 (C13) e 18 meses de idade (C18) e inteiros (INT)

\begin{tabular}{lrrrr}
\hline Característica & \multicolumn{1}{c}{ Tratamento } & \multicolumn{2}{c}{ P F Contraste ${ }^{1}$} \\
\cline { 2 - 4 } & \multicolumn{1}{c}{ C13 } & C18 & INT \\
\hline Peso de abate, kg & $371,73 \mathrm{~b} \pm 4,60$ & $379,81 \mathrm{~b} \pm 4,60$ & $395,00 \mathrm{a} \pm 4,69$ & $* *$ \\
Peso de carcaça quente, kg & $198,03 \mathrm{~b} \pm 3,11$ & $203,56 \mathrm{~b} \pm 3,11$ & $214,89 \mathrm{a} \pm 3,17$ & $* *$ \\
Peso de carcaça fria, kg & $193,33 \mathrm{~b} \pm 2,95$ & $199,53 \mathrm{~b} \pm 2,95$ & $212,21 \mathrm{a} \pm 3,01$ & $* * *$ \\
Rendimento de carcaça quente, \% & $53,25 \pm 0,51$ & $53,63 \pm 0,51$ & $54,40 \pm 0,52$ & ns \\
Rendimento de carcaça fria, \% & $51,99 \mathrm{~b} \pm 0,46$ & $52,58 \mathrm{ab} \pm 0,46$ & $53,71 \mathrm{a} \pm 0,47$ & ns \\
Perdas por resfriamento, \% & $2,29 \pm 0,56$ & $1,96 \pm 0,56$ & $1,18 \pm 0,57$ & $\mathrm{~ns}$ \\
\hline
\end{tabular}

a, b Médias seguidas por letras diferentes, na linha, diferem $(P<0,05)$ pelo teste Tukey.

${ }^{1}$ Contraste entre novilhos castrados (C13 e C18) e INT ( $\mathrm{ns}=$ não-significativo; $\left.{ }^{* \star P} P<0,01 ;{ }^{* \star *} \mathrm{P}<0,001\right)$. 
Silva (2005) estudou métodos (burdizzo ou faca) e épocas de castração (15 dias antes ou ao início do confinamento) e verificou que os manejos utilizados não influenciaram o ganho de peso (103 dias de confinamento) e peso de abate dos castrados, sendo estes inferiores aos inteiros. Além disso, animais castrados, independentemente do método, quando castrados 15 dias antes do início do confinamento, tiveram peso de carcaça quente inferior às demais situações de manejo, mas não afetaram o rendimento. Esse resultado, atribuído por esse autor ao estresse da castração que ocasionou perda de peso no período pós-castração/préconfinamento, é próximo ao obtido neste experimento para os C18.

O rendimento de carcaça quente não diferiu entre os tratamentos $(\mathrm{P}>0,05)$. No entanto, os bovinos INT apresentaram maiores rendimentos de carcaça fria em relação aos C13. Para os C18, os valores foram intermediários entre os INT e C13 ( $P>0,05)$. Analisando a condição sexual sobre as características da carcaça de novilhos Hereford, Restle \& Vaz (1997) verificaram similaridade para rendimentos de carcaça quente e fria. Resultados concordantes foram relatados por Field (1971), Seideman et al. (1982), Morgan et al. (1993) e Euclides Filho et al. (2001). Porém, Gerrard et al. (1987) e Tullio (2004) encontraram superioridade dos inteiros quanto ao rendimento de carcaça quente.

Nas perdas por resfriamento da carcaça, houve similaridade entre os diferentes tratamentos estudados. Menores perdas representam melhor rendimento de carcaça fria, fato muito importante para os frigoríficos quando comercializam as carcaças. Segundo Müller (1987), esta característica é regulada pelo grau de acabamento da carcaça ou pela espessura de gordura, que funciona como isolante, evitando as perdas por desidratação. Assim, carcaças com maior grau de acabamento apresentam menores perdas durante o processo de resfriamento da carcaça. Neste estudo, as carcaças dos animais castrados apresentaram maior grau de acabamento em relação aos inteiros. No entanto, esta diferença não foi suficiente para causar diferenças significativas nas perdas por resfriamento da carcaça.

Além da espessura de gordura, Pacheco et al. (2005) comentaram que as características avaliadas na carcaça que expressam musculosidade, como conformação, que representa uma avaliação subjetiva do volume muscular, AOL, espessura de coxão e perímetro de braço, apresentam correlação negativa e de média magnitude com as perdas por resfriamento da carcaça. No entanto, neste estudo este resultado não foi verificado (Tabela 4). Diversos estudos que avaliaram as características da carcaça de bovinos INT em relação aos castrados (Arthaud et al., 1977; Restle \& Vaz, 1997; Restle et al., 2000 b) demonstraram que os inteiros apresentaram vantagens para características que expressam musculosidade.

Não houve diferenças $(\mathrm{P}>0,05)$ das características métricas entre os tratamentos (Tabela 2). Estas características são importantes, pois geralmente apresentam relação positiva e de média a alta magnitude com peso de abate do animal (Pacheco et al., 2005). Neste estudo (Tabela 4), os coeficientes de correlação verificados para comprimento de carcaça $(0,23)$ e comprimento do braço $(0,34)$ com peso de abate foram significativos $(\mathrm{P}<0,05)$. Já o perímetro do braço correlacionou-se significativamente com peso $(0,66)$ e porcentagem de dianteiro $(0,31)$ (Tabela 5).

Devido à ação dos hormônios androgênicos em animais inteiros, espera-se maior hipertrofia muscular principalmente no dianteiro, devido ao dimorfismo sexual (Seideman et al., 1982), e, conseqüentemente, maior perímetro do braço. No entanto, os resultados de estudos que avaliaram características métricas da carcaça são divergentes. Nos trabalhos de Müller \& Restle (1983), Restle \& Vaz (1997), Restle et al. (2000 b) e Silva (2005) não houve diferença entre animais inteiros e castrados para características métricas da carcaça. Todavia, maior comprimento de carcaça para animais inteiros

Tabela 2 - Médias e erros-padrão para comprimento de carcaça, comprimento do braço, perímetro do braço, área do olho-de-lombo (AOL), AOL por $100 \mathrm{~kg}$ do peso de carcaça fria (PCF), espessura de gordura (EG) e EG por $100 \mathrm{~kg}$ de PCF de bovinos Nelore castrados aos 13 (C13), aos 18 meses de idade (C18) e inteiros (INT)

\begin{tabular}{|c|c|c|c|c|}
\hline \multirow[t]{2}{*}{ Característica } & \multicolumn{3}{|c|}{ Tratamento } & \multirow[t]{2}{*}{$\mathrm{P}<\mathrm{F}$ Contraste ${ }^{1}$} \\
\hline & C13 & C18 & INT & \\
\hline Comprimento de carcaça, cm & $129,29 \pm 0,61$ & $130,11 \pm 0,61$ & $130,54 \pm 0,62$ & ns \\
\hline Comprimento do braço, $\mathrm{cm}$ & $42,35 \pm 0,35$ & $41,92 \pm 0,35$ & $42,04 \pm 0,35$ & ns \\
\hline Perímetro do braço, cm & $32,32 \pm 0,29$ & $32,38 \pm 0,29$ & $33,02 \pm 0,29$ & ns \\
\hline $\mathrm{AOL}, \mathrm{cm}^{2}$ & $56,59 b \pm 1,43$ & $57,48 \mathrm{ab} \pm 1,43$ & $61,23 a \pm 1,45$ & $*$ \\
\hline $\mathrm{AOL} / 100 \mathrm{~kg}$ PCF, $\mathrm{cm}^{2}$ & $29,34 \pm 0,60$ & $28,84 \pm 0,60$ & $28,82 \pm 0,61$ & ns \\
\hline $\mathrm{EG}, \mathrm{mm}$ & $3,89 a \pm 0,18$ & $3,70 \mathrm{a} \pm 0,18$ & $3,04 b \pm 0,18$ & $* *$ \\
\hline EG/100 kg PCF, mm & $2,01 \mathrm{a} \pm 0,09$ & $1,87 \mathrm{a} \pm 0,09$ & $1,44 b \pm 0,09$ & $* * *$ \\
\hline
\end{tabular}

a, b Médias seguidas por letras diferentes, na linha, diferem $(P<0,05)$ pelo teste Tukey.

${ }^{1}$ Contraste entre novilhos castrados (C13 e C18) e INT (ns = não-significativo; ${ }^{* \star P} P<0,01 ;{ }^{* * * P}<0,001$ ). 
em relação aos castrados foi relatado nos estudos de Restle et al. (1994 a) (123,7 vs. 120,3 cm) e Tullio (2004) (125,0 vs. 121,5 cm). Já Restle et al. (1996) verificaram maiores valores para perímetro de braço e espessura de coxão, reflexo do maior grau de musculosidade, para os inteiros em relação aos castrados.

Verificou-se superioridade $(\mathrm{P}<0,05)$ da $\mathrm{AOL}$ - uma das características que refletem a musculosidade da carcaça dos animais inteiros em relação aos castrados aos 13 meses de idade, sendo que os castrados aos 18 meses de idade apresentaram valores intermediários. Pela análise de contraste, houve diferença significativa entre animais inteiros e castrados (13 e 18 meses). No entanto, nota-se que esta característica está diretamente relacionada ao peso de carcaça, pois, quando ajustada para $100 \mathrm{~kg}$ de peso de carcaça fria, houve similaridade entre os tratamentos avaliados. Este resultado pode ser confirmado também analisando os coeficientes de correlação apresentados na Tabela 4. Resultados concordantes foram relatados nos estudos de Champagneetal.(1969), Morais etal.(1993), Restleet al.(1996), Vaz et al.(2001) e Tullio (2004).

Os animais inteiros apresentaram menores valores para espessura de gordura em relação aos castrados aos 13 e 18 meses de idade, tanto expressa em valores absolutos, quanto ajustada para $100 \mathrm{~kg}$ de peso de carcaça fria (Tabela 2). De acordo com a análise de contraste, o comportamento foi semelhante. Diversos estudos evidenciam menores valores (Arthaud et al., 1977; Müller \& Restle, 1983; Gerrard et al., 1987; Morgan et al., 1993; Restle et al., 1994 a; Restle et al., 1996; Restle et al., 2000 b; Padua et al., 2004; Tullio, 2004) ou valores similares (Restle \& Vaz, 1997) para espessura de gordura das carcaças de animais inteiros em relação aos castrados. Conforme Restle \& Vaz (1997), a principal resistência em abater animais inteiros, por parte dos frigoríficos, reside no fato desses apresentarem escassa gordura de cobertura na carcaça, causando escurecimento da carcaça e maior perda de líquidos, durante o resfriamento. Costa et al. (2002) comentam que a espessura de gordura exigida nas carcaças pelos frigoríficos brasileiros situa-se entre 3 e $6 \mathrm{~mm}$. Abaixo de $3 \mathrm{~mm}$, ocorre o escurecimento da parte externa dos músculos que recobrem a carcaça, depreciando seu valor comercial. Segundo os mesmos autores, cobertura de gordura superior a $6 \mathrm{~mm}$ representa recorte com eliminação do excesso de gordura de cobertura antes da pesagem da carcaça, o que acarreta maior custo operacional para o frigorífico.

Neste estudo, nota-se que a gordura de cobertura das carcaças dos animais inteiros ficou acima do limite mínimo de $3 \mathrm{~mm}$, indicando que é possível obter grau de acabamento satisfatório quando os mesmos são submetidos a condições nutricionais favoráveis, pela terminação em confinamento. No estudo de Arthaud et al. (1977), que avaliaram as carcaças de machos submetidos a alto nível nutricional, verificou-se que animais INT apresentaram similaridade para espessura de gordura em relação aos castrados, quando abatidos aos 12, 15 ou 18 meses de idade. Da mesma maneira, Restle \& Vaz (1997) relataram que, com bom nível alimentar na fase de terminação, trabalhando com novilhos jovens e composição genética taurina, animais INT apresentaram carcaças com grau de acabamento satisfatório. No entanto, Padua et al. (2004), trabalhando com bovinos Nelore e cruzados com Angus e Simental, verificaram que houve maior deposição de gordura subcutânea (medida pelo grau de acabamento da carcaça com escore de 1 a 5) tanto nos animais castrados aos seis meses de idade $(1,67)$, quanto nos castrados que receberam reposição hormonal com Synovex ${ }^{\circledR}(2,17)$, do que nos animais inteiros $(1,33)$, em novilhos confinados aos oito meses e abatidos aos 15 meses de idade (superjovens).

Quando expressos em valores absolutos, novilhos inteiros apresentaram maiores valores de dianteiro $(\mathrm{P}<0,001)$ e traseiro $(\mathrm{P}<0,01)$ em relação a ambos os tratamentos de animais castrados, conforme análise de contraste (Tabela 3). Isto devido ao maior peso de carcaça fria para os inteiros,

Tabela 3 - Médias e erros-padrão para peso absoluto e percentual de dianteiro, ponta de agulha e traseiro da carcaça de bovinos Nelore castrados aos 13 (C13) e 18 meses de idade (C18) e inteiros (INT)

\begin{tabular}{|c|c|c|c|c|c|}
\hline \multirow[t]{2}{*}{ Característica } & & \multicolumn{3}{|c|}{ Tratamento } & \multirow[t]{2}{*}{$\mathrm{P}<\mathrm{F}$ Contraste ${ }^{1}$} \\
\hline & & C13 & C18 & INT & \\
\hline \multirow[t]{2}{*}{ Dianteiro } & $\mathrm{kg}$ & $37,05 b \pm 0,68$ & $38,75 b \pm 0,68$ & $42,62 \mathrm{a} \pm 0,70$ & $* * *$ \\
\hline & $\%$ & $38,33 b \pm 0,25$ & $38,82 b \pm 0,25$ & $40,13 \mathrm{a} \pm 0,25$ & $* * *$ \\
\hline \multirow{2}{*}{ Ponta de agulha } & $\mathrm{kg}$ & $10,72 \pm 0,22$ & $10,72 \pm 0,22$ & $10,86 \pm 0,23$ & ns \\
\hline & $\%$ & $11,09 a \pm 0,13$ & $10,73 a \pm 0,13$ & $10,22 b \pm 0,14$ & $* * *$ \\
\hline \multirow[t]{2}{*}{ Traseiro } & $\mathrm{kg}$ & $50,02 b \pm 0,70$ & $51,30 \mathrm{ab} \pm 0,70$ & $53,25 a \pm 0,71$ & $* *$ \\
\hline & $\%$ & $51,77 a \pm 0,26$ & $51,46 a \pm 0,26$ & $50,24 b \pm 0,26$ & $* * *$ \\
\hline
\end{tabular}

a, b Médias seguidas por letras diferentes, na linha, diferem $(P<0,05)$ pelo teste Tukey.

${ }_{1}^{1}$ Contraste entre novilhos castrados (C13 e C18) e INT (ns = não-significativo; $\left.{ }^{* * P<0,01 ; ~}{ }^{* * *} \mathrm{P}<0,001\right)$. 
conforme apresentado na Tabela 1. Restle \& Vaz (1997) relataram maior peso de dianteiro (41,7 vs. $35,0 \mathrm{~kg}$ ) para as carcaças de novilhos inteiros em relação aos castrados, mas similaridade quanto ao peso do traseiro.

Quando avaliada a porcentagem dos cortes primários, bovinos inteiros apresentaram maior proporção de dianteiro e menor de ponta de agulha e traseiro em relação às carcaças de animais castrados aos 13 e 18 meses de idade. Este comportamento da alteração na proporção dos cortes primários da carcaça é atribuído ao efeito dos hormônios masculinos responsáveis pelo dimorfismo sexual, característico do reprodutor macho. Estes resultados são concordantes aos relatados por Restle et al. (1996, 2000b). No estudo de Soares (2005), com animais
Nelore inteiros, castrados aos 8 e 15 meses, verificou-se maior porcentagem de dianteiro e menor de ponta de agulha para os inteiros em relação a ambos castrados e menor porcentagem de traseiro em relação aos castrados aos oito meses de idade. Segundo Seideman et al. (1982) e Restle \& Vaz (1997), a testosterona é responsável por outras características relacionadas ao dimorfismo sexual que prejudicam o aspecto da carcaça, como o aumento dos valores da porcentagem de dianteiro. Isto tem reflexo no aspecto comercial da carcaça, pois os cortes situados no dianteiro são menos valorizados que os situados no traseiro. No estudo de Morais et al. (1993), evidenciou-se que animais inteiros apresentaram, além de maior valor percentual de dianteiro, maior percentual dos cortes,

Tabela 4 - Coeficientes de correlação de Pearson $(r)$ gerais e probabilidade $(P)$ entre as características da carcaça

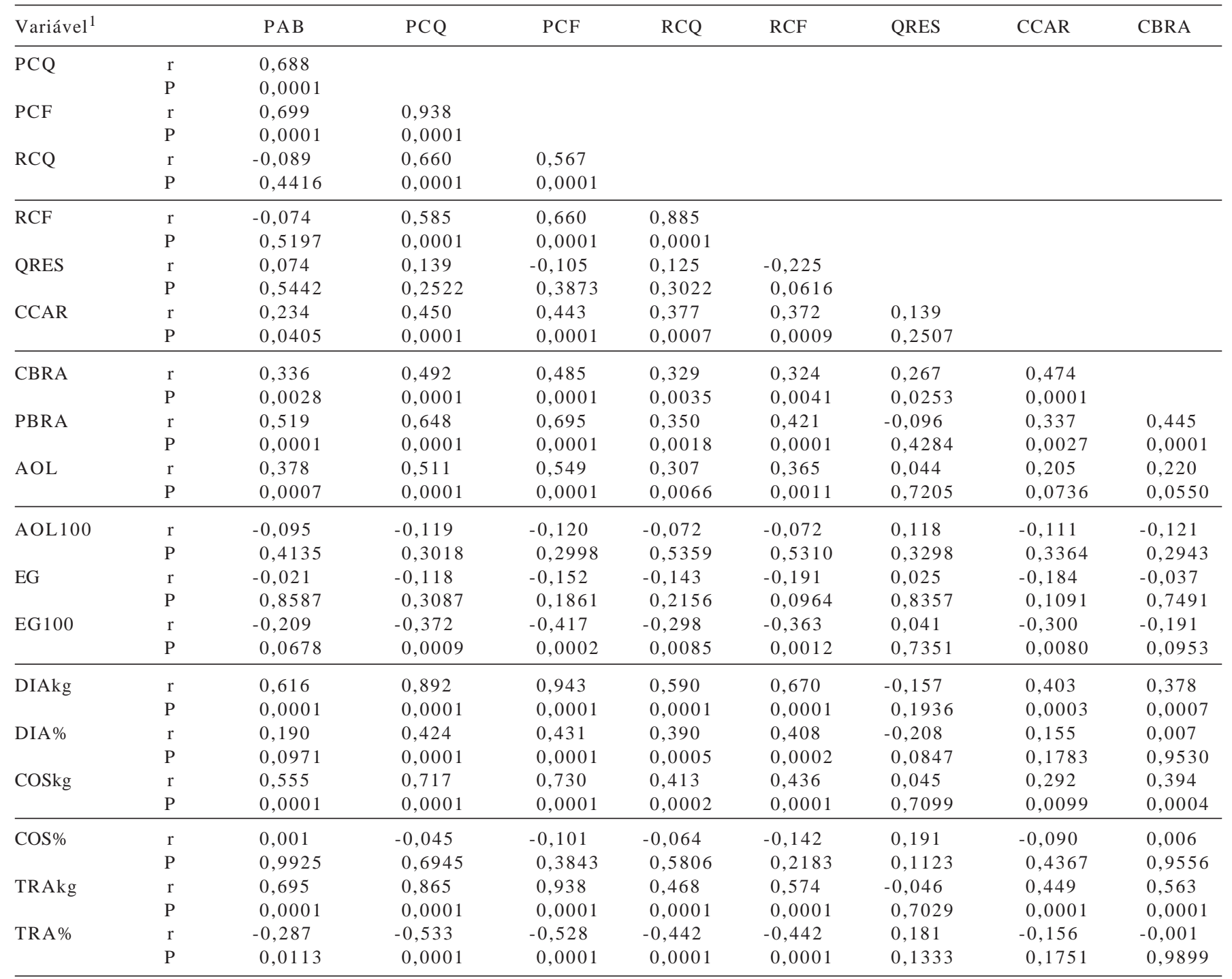

${ }^{1} \mathrm{PAB}=$ peso de abate; $\mathrm{PCQ}=$ peso de carcaça quente; $\mathrm{PCF}=$ peso de carcaça fria; $\mathrm{RCQ}=$ rendimento de carcaça quente; $\mathrm{RCF}=$ rendimento de carcaça fria; QRES = perda no resfriamento; CCAR = comprimento de carcaça; CBRA = comprimento do braço; PBRA = perímetro do braço; AOL = área de olhode-lombo; AOL100 = AOL/100 kg PCF; EG = espessura de gordura; EG100 = EG/100 kg PCF; DIAkg = kg de dianteiro; DIA\% = porcentagem de dianteiro; COSkg = kg de costilhar; COS $\%=$ porcentagem de costilhar; TRAkg = kg de traseiro; TRA\% = porcentagem de traseiro. 
Tabela 5 - Coeficientes de correlação de Pearson $(r)$ gerais e probabilidade $(P)$ entre as características da carcaça

\begin{tabular}{|c|c|c|c|c|c|c|c|c|c|c|c|}
\hline Variável $^{1}$ & & PBRA & AOL & AOL 100 & EG & EG100 & DIAkg & DIA\% & COSkg & COS\% & TRAkg \\
\hline AOL & $\mathrm{P}$ & 0,0017 & & & & & & & & & \\
\hline AOL 100 & $\mathrm{r}$ & $-0,107$ & 0,761 & & & & & & & & \\
\hline \multirow[t]{2}{*}{ EG } & $\mathrm{r}$ & $-0,153$ & $-0,119$ & $-0,015$ & & & & & & & \\
\hline & $\mathrm{P}$ & 0,1853 & 0,3041 & 0,8999 & & & & & & & \\
\hline EG100 & $\mathrm{r}$ & $-0,335$ & $-0,256$ & 0,026 & 0,959 & & & & & & \\
\hline \multirow[t]{2}{*}{ DIAkg } & $\mathrm{r}$ & 0,658 & 0,490 & $-0,148$ & $-0,272$ & $-0,506$ & & & & & \\
\hline & $\mathrm{P}$ & 0,0001 & 0,0001 & 0,1981 & 0,0169 & 0,0001 & & & & & \\
\hline \multirow[t]{2}{*}{ DIA\% } & $\mathrm{r}$ & 0,314 & 0,159 & $-0,152$ & $-0,415$ & $-0,492$ & 0,706 & & & & \\
\hline & $\mathrm{P}$ & 0,0054 & 0,1685 & 0,1873 & 0,0002 & 0,0001 & 0,0001 & & & & \\
\hline \multirow[t]{2}{*}{ COSkg } & $\mathrm{r}$ & 0,485 & 0,479 & 0,008 & 0,161 & $-0,058$ & 0,561 & $-0,034$ & & & \\
\hline & $\mathrm{P}$ & 0,0001 & 0,0001 & 0,9417 & 0,1622 & 0,6194 & 0,0001 & 0,7717 & & & \\
\hline \multirow[t]{2}{*}{ TRA\% } & r & $-0,333$ & $-0,253$ & 0,113 & 0,266 & 0,382 & $-0,739$ & $-0,880$ & $-0,328$ & 0,126 & $-0,201$ \\
\hline & $\mathrm{P}$ & 0,0031 & 0,0261 & 0,3261 & 0,0192 & 0,0006 & 0,0001 & 0,0001 & 0,0035 & 0,2742 & 0,0791 \\
\hline
\end{tabular}

1 PBRA = perímetro do braço; $A O L=$ área de olho-de-lombo; $A O L 100=A O L / 100 \mathrm{~kg} \mathrm{PCF} ; E G=$ espessura de gordura; EG100 = EG/100 kg PCF; DIAkg = $\mathrm{kg}$ de dianteiro; $\mathrm{DIA} \%=$ porcentagem de dianteiro; $\mathrm{COSkg}=\mathrm{kg}$ de costilhar; $\mathrm{COS} \%=$ porcentagem de costilhar; TRAkg = $\mathrm{kg}$ de traseiro; TRA $\%=$ porcentagem de traseiro.

sendo que os animais castrados apresentaram maior porcentagem de cortes oriundos do traseiro.

\section{Conclusões}

A utilização de bovinos inteiros promoveu maior peso de abate e, conseqüentemente, maiores pesos de carcaça quente e fria, além de resultar em carcaças com maior área de olho-de-lombo. A castração de bovinos conferiu às carcaças maior espessura de gordura e, conseqüentemente, melhor acabamento. Com relação aos cortes comerciais, animais inteiros apresentaram menor percentual de traseiro e maior de dianteiro na carcaça. A terminação em confinamento de bovinos Nelore inteiros resultou em maior benefício para as características da carcaça avaliadas.

\section{Literatura Citada}

ARTHAUD, V.H.; MANDIGO, R.W.; KOCH, R.M. et al. Carcass composition, quality and palatability attributes of bulls and steers feed different energy levels and killed at four ages. Journal of Animal Science, v.44, n.1, p.53-64, 1977.

CHAMPAGNE, J.R.; CARPENTER, J.W.; HENTGES JR., J.F. et al. Feedlot performance and carcass characteristics of young bulls and steers castrated at four ages. Journal of Animal Science, v.29, n.6, p.887-890, 1969.

COSTA, E.C.; RESTLE, J.; VAZ, F.N. et al. Características da carcaça de novilhos Red Angus superprecoces abatidos com diferentes pesos. Revista Brasileira de Zootecnia, v.31, n.1, p.119-128, 2002.

EUCLIDES FILHO, K.; FEIJÓ, G.L.D.; FIGUEIREDO, G.R. et al. Efeito de idade à castração e de grupos genéticos sobre o desempenho em confinamento e características de carcaça. Revista Brasileira de Zootecnia, v.30, n.1, p.71-76, 2001. FIELD, R.A. Effect of castration on meat quality and quantity. Journal of Animal Science, v.32, n.5, p.849-856, 1971.

GERRARD, D.E.; JONES, S.J.; ABERLE, E.D. et al. Collagen stability, testosterone secretion and meat tenderness in growing bulls and steers. Journal of Animal Science, v.65, n.5, p.12361242, 1987.

LEE, C.Y.; HENRICKS, D.M.; SKELLEY, G.C. et al. Growth and hormones response of intact and castrate male cattle to trenbolone acetate and estradiol. Journal of Animal Science, v.68, n.9, p.2682-2689, 1990.

MORAIS, C.A.C.; FONTES, C.A.A.; LANA, R.P. et al. Influência da monensina sobre o rendimento de carcaça e de seus cortes básicos e outras características, em bovinos castrados e não castrados. Revista da Sociedade Brasileira de Zootecnia, v.22, n.1, p.72-80, 1993.

MORGAN, J.B.; WHEELER, T.L.; KOOHMARAIE, M. et al. Effect of castration on myofibrillar protein turnover, endogenous proteinase activities, and muscle growth in bovine skeletal muscle. Journal of Animal Science, v.71, n.2, p.408-414, 1993.

MÜLLER, L. Normas para avaliação de carcaças e concurso de carcaças de novilhos. 2.ed. Santa Maria: Universidade Federal de Santa Maria, 1987. 31p.

MÜLLER, L.; RESTLE, J. Carcass characteristics of steers and young bulls. In: EUROPEAN CONGRESS OF MEAT RESEARCHER WORKERS, 29., 1983, Parma. Proceedings... Parma: CERCA, 1983. p.530-535.

NATIONAL RESEARCH COUNCIL - NRC. Nutrient requirements of domestic animals. 7.ed. Washington, D.C.: National Academy Press, 1996. 242p.

PACHECO, P.S.; SILVA, J.H.S.; RESTLE, J. et al. Características quantitativas da carcaça de novilhos jovens e superjovens de diferentes grupos genéticos. Revista Brasileira de Zootecnia, v.34, n.5, p.1666-1677, 2005.

PADUA, J.T.; MAGNABOSCO, C.U.; SAINZ, R.D. et al. Genótipo e condição sexual no desempenho e nas características de carcaça de bovinos de corte superjovens. Revista Brasileira de Zootecnia, v.33, n.6, p.2330-2342, 2004 (supl. 3). 
PEREIRA, L.P. Desenvolvimento ponderal em peso e medidas corporais de bovinos de corte inteiros ou castrados de diferentes grupos genéticos. Santa Maria: Universidade Federal de Santa Maria, 1999. 90p. Dissertação (Mestrado em Zootecnia) - Universidade Federal de Santa Maria, 1999.

RESTLE, J.; ALVES FILHO, D.C.; FATURI, C. et al. Desempenho na fase de crescimento de machos bovinos inteiros ou castrados de diferentes grupos genéticos. Revista Brasileira de Zootecnia, v.29, n.4, p.1036-1043, 2000a.

RESTLE, J.; GRASSI, C.; FEIJÓ, G.L.D. Características de carcaça de bovinos de corte inteiros ou castrados em diferentes idades. Pesquisa Agropecuária Brasileira, v.29, n.10, p.1603-1607, 1994a.

RESTLE, J.; GRASSI, C.; FEIJÓ, G.L.D. Evolução do peso de bovinos de corte inteiros ou castrados em diferentes idades. Pesquisa Agropecuária Brasileira, v.29, n.10, p.1631-1635, 1994 b.

RESTLE, J.; GRASSI, C.; FEIJÓ, G.L.D. Características das carcaças e da carne de bovinos inteiros ou submetidos a duas formas de castração, em condições de pastagem. Revista Brasileira de Zootecnia, v.25, n.2, p.334-344, 1996.

RESTLE, J.; VAZ, F.N. Aspectos quantitativos da carcaça de machos Hereford inteiros ou castrados, abatidos aos quatorze meses. Pesquisa Agropecuária Brasileira, v.32, n.10, p.1091-1095, 1997.

RESTLE, J.; VAZ, F.N.; ALVES FILHO, D.C. Machos não castrados para produção de carne. In: RESTLE, J. (Ed.) Confinamento, pastagens e suplementação para produção de bovinos de corte. Santa Maria: Universidade Federal de Santa Maria, 1999. p.215-231.

RESTLE, J.; VAZ, F.N.; FEIJÓ, G.L.D. et al. Características de carcaça de bovinos de corte inteiros ou castrados de diferentes composições raciais Charolês x Nelore. Revista Brasileira de Zootecnia, v.29, n.5, p.1371-1379, 2000b.
RIBEIRO, E.L.A.; HERNANDEZ, J.A.; ZANELLA, E.L. et al. Growth and carcass characteristics of pasture fed LHRH immunocastrated, castrated and intact Bos indicus bulls. Meat Science, v.68, n.2, p.285-290, 2004.

RUIZ, M.R.; MATSUSHITA, M.; VISENTAINER, J.V. et al. Proximate chemical composition and fatty acid profiles of Longissimus thoracis from pasture fed LHRH immunocastrated, castrated and intact Bos indicus bulls. South African Journal of Animal Science, v.35, n.1, p.13-18, 2005.

STATISTICAL ANALYSIS SYSTEMS - SAS. User's guide. Version 6, Cary: SAS Institute, 1997. v.2, 1052p.

SEIDEMAN, S.C.; CROSS, H.R.; OLTJEN, R.R. et al. Utilization of the intact male for red meat production: a review. Journal of Animal Science, v.55, n.4, p.826-840, 1982.

SILVA, J.R.M. Desempenho e características de carcaças de bovinos Nelore e F1 Pardo Suíço $x$ Nelore, submetidos a diferentes manejos de castração e confinados. Lavras: Universidade Federal de Lavras, 2005. 66p. Dissertação (Mestrado em Zootecnia) - Universidade Federal de Lavras, 2005.

SOARES, L. Composição, rendimento de carcaça e desempenho de bovinos inteiros e castrados em diferentes idades, recriados a pasto e terminados em confinamento. Lavras: Universidade Federal de Lavras, 2005. 74p. Dissertação (Mestrado em Zootecnia) - Universidade Federal de Lavras, 2005.

TULLIO, R.R. Estratégias de manejo para a produção intensiva de bovinos visando à qualidade da carne. Jaboticabal: Universidade Estadual Paulista, 2004. 107p. Tese (Doutorado em Zootecnia) - Universidade Estadual Paulista, 2004.

VAZ, F.N.; RESTLE, J.; FEIJÓ, G.L.D. et al. Qualidade e composição química da carne de bovinos de corte inteiros ou castrados de diferentes grupos genéticos Charolês x Nelore. Revista Brasileira de Zootecnia, v.30, n.2, p.518-525, 2001. 